\title{
UN REY PARA EL OLVIDO: LA FIGURA DE ALFREDO EL GRANDE A TRAVÉS DE LA PANTALLA
}

\author{
Alberto Robles Delgado ${ }^{1}$ \\ Universidad de Alicante
}

Recibido 17 de julio de 2020

Aceptado: 21 de enero de 2021

\begin{abstract}
Resumen
Alfredo el Grande es, sin duda, una figura importante no solo de la historia inglesa, sino de la propia Edad Media europea. Sus políticas para hacer frente a la invasión nórdica de Inglaterra, así como sus reformas culturales, educativas y jurídicas, han convertido a este rey en un personaje reverenciado en los círculos intelectuales ingleses, sobre todo en el siglo XIX. Resulta llamativo que aun así este monarca no tenga una presencia mucho más destacada dentro de los medios cinematográficos y audiovisuales, los medios artísticos de masas por antonomasia del siglo XX y XXI. Es justo el objetivo del presente trabajo trazar la trayectoria mediática y popular de este rey, así como analizar su representación y construcción en las producciones audiovisuales que han tratado su figura.
\end{abstract}

\section{Palabras clave}

Cine, televisión, anglosajón, vikingos, Inglaterra.

\begin{abstract}
Alfred the Great is, without a doubt, an important figure not only in English history, but also in that of the European Middle Ages. His policies for dealing with the Nordic invasion of England, as well as his cultural, educational and legal reforms, have made this king a revered figure in English intellectual circles, especially in the 19th century. It is striking that, in spite of his popularity, this monarch does not have a more prominent presence within audiovisual media, which is the artistic mass media par excellence of the twentieth and twenty-first century. The objective of the present work is to investigate the historical popularity and audiovisual trajectory of this king, as well as to analyze his representation in the cinema and television productions that have dealt with him.
\end{abstract}

\section{Keywords}

Cinema, television, anglo-saxon, vikings, England.

\section{Resumo}

Alfredo o Grande é, sem dúvida, uma figura importante, não só da história inglesa, mas da propria Idade Média europeia. Suas políticas para fazer frente à invasão nórdica da Inglaterra, assim como suas reformas culturais, educativas e jurídicas, têm convertido este rei em uma personagem reverenciada nos círculos intelectuais ingleses, sobretudo no século XIX. Resulta surpreendente que este rei não tenha uma presença muito mais importante dentro dos meios cinematográficos e audiovisuais, meios artísticos de massa por excelência dos séculos XX e XXI. É justo o objetivo deste trabalho

\footnotetext{
1 Universidad de Alicante. Correo electrónico: alb14j52@hotmail.com. OrCiD: https://orcid.org/00000002-0413-7608.
} 
desenhar a trajetória midiática e popular este rei, assim como analisar sua representação e construção nas produções audiovisuais sobre sua figura.

Palavras-chave

Cinema, televisão, anglo-saxão, vikings, Inglaterra.

\section{Introducción}

Alfredo el Grande es una de las personalidades más influyentes de la historia de Inglaterra. Ya sea en su papel como líder de la resistencia anglosajona frente a la invasión vikinga, como artífice de una renovación educativa y cultural o como promotor y compilador de crónicas (como la celebérrima Crónica Anglosajona), los logros y hazañas de este monarca son extraordinarios. No es de extrañar que sea el único rey de Inglaterra que reciba el calificativo de "the Great".

Con este curriculum no debería sorprendernos que en multitud de ocasiones la figura de este rey haya sido invocada como reflejo de las grandes virtudes de la cultura inglesa, como icono nacional, o como legitimador de acciones políticas. Esta veneración por su figura alcanzará su punto álgido durante el periodo victoriano donde se desarrollará un auténtico culto devocional a su imagen, que cristalizó en la celebración del milenio del fallecimiento del monarca en el año 1901.

Este fervor irá languideciendo durante el siglo XX, convirtiéndose en un personaje muy poco presente en la cultura popular. Una muestra de este desinterés será su escasa presencia en el medio audiovisual, lo cual llama poderosamente la atención ante un personaje de esta magnitud.

Si rastreamos su presencia a través de la pequeña o gran pantalla solamente encontraremos tres producciones que aborden la figura de este rey: la película de Clive Donner, Alfred the Great (1969), y las series de television Vikings (Michael Hirst, 2013) y The Last Kingdom (2015).

Van a ser justamente estas tres producciones el objeto de estudio de este trabajo en el que contextualizaremos estas creaciones, esbozaremos una trayectoria sobre la popularidad y el interés que este personaje ha suscitado en el medio audiovisual y también plantearemos un análisis más detallado tanto de las principales características del Alfredo cinematográfico, como de los discursos imperantes de carácter histórico que podemos encontrar en este corpus.

Todo ello bajo el amparo metodológico y discursivo de la escuela norteamericana, concretamente, siguiendo las enseñanzas de Robert A. Rosenstone, y utilizando corrientes teóricas propias del ámbito de la posmodernidad o los New Cultural Studies, que conforman lo que hoy día conocemos como los estudios sobre recepción. Con la

\footnotetext{
Aunque normalmente traducido en español como "el grande", sería más correcto utilizar el adjetivo "magno", al igual que se utiliza con otros personajes como Alejandro Magno (Alexander the Great) o Carlomagno (Charles the Great).
} 
idea, no de centrarnos en la "veracidad" o "historicidad" de las representaciones sobre este monarca, sino con la de contextualizar esta figura en el imaginario popular y en el tiempo de sus producciones audiovisuales, para obtener una imagen más amplia sobre cómo se ha entendido y recibido a Alfredo el Grande.

\section{Rex Anglorum}

El reinado de Alfredo comenzó en un momento de auténtica crisis, en el que la práctica totalidad del territorio hoy conocido como Inglaterra se encontraba bajo dominio nórdico y los anglosajones luchaban por su propia supervivencia.

La presencia de los vikingos en Inglaterra se remonta a finales del siglo VIII, en el que pequeñas partidas de talante pirático asaltaban monasterios y asentamientos desprotegidos en busca de botín y riquezas. El hito más famoso, y que de alguna manera da inicio a la conocida como Era Vikinga, ${ }^{3}$ fue el ataque a la abadía de Lindisfarne, en la costa northumbria, en el año 793 de nuestra era. En torno al año 850 se produce un cambio sustancial en estas actividades de piratería y los vikingos comienzan a invernar en territorio inglés, ampliando el radio y la frecuencia de sus saqueos, y convirtiéndose en una presencia más o menos fija. Pero sin duda el punto de inflexión llego, según nos narran las crónicas, en el año 865 cuando el conocido como "Gran ejército pagano"4 arriba a las costas inglesas y comienzan a ocupar y conquistar territorios. ${ }^{5}$

A la llegada de los vikingos, Inglaterra se encontraba dividida en una serie de reinos cristianos que luchaban entre sí por la preeminencia política de los territorios bajo dominio anglosajón (es decir el centro, sur y este de la isla). Esta etapa es comúnmente conocida como la heptarquía anglosajona. ${ }^{6}$

Durante las primeras décadas del siglo IX estas luchas de poder fueron favorables para el reino de Wessex y su monarca Egbert, quien había conseguido convertirse en la au-

Tradicionalmente se ha considerado la Era Vikinga como un periodo comprendido entre el año 793, con el asalto a Lindisfarne, y el año 1066, donde la batalla de Stamford Bridge y Hasting marcaron el final de dicho periodo. Esta división cronológica es debatida a día de hoy, dado su fuerte talante anglocentrista, y se han establecido cronologías alternativas como por ejemplo del 800 al 1050, en base a cambios sustanciales que se producen dentro de la propia cultura escandinava como la propagación de la actividad piratica o la cristianización. LANGER, "Era Viking”, p. 212.

4 Este contingente aparece nombrado en la Crónica Anglosajona como mycel here (Gran ejército pagano), una hueste de numero incierto (se estima que en torno a pocos miles de hombres) comandada por diversos caudillos y reyes vikingos, entre los cuales destaca la presencia de los supuestos hijos del legendario Ragnar Lothbrok (Ivar, Halfdan y Ubba), que llevaron a cabo una serie de exitosas campañas de conquista y asentamiento en territorio anglosajón. Vilar Oliveira, "Grande Armada Danesa”, p. 323.

5 Dowham, "Vikings in England", p. 342.

6 Esta palabra hace referencia a la división territorial de Inglaterra en torno a siete reinos anglosajones (Northumbria, Mercia, Anglia Oriental, Wessex, Sussex, Essex y Kent) que establece la obra de Beda el Venerable (672-735). Este panorama político muto con frecuencia y la aparición y desaparición de pequeños reinos fue una constante entre los siglos V al VIII. Por ejemplo, a la llegada del Gran ejército pagano serán solo cuatro los reinos que perduren: Northumbria, Mercia, Anglia Oriental y Wessex. DomínGuez GonZÁlez, La Inglaterra anglosajona, p. 51. 
toridad incontestable del sur de Inglaterra e incluso extender su control a otros reinos como Mercia, logrando el título de Bretwalda. ${ }^{7}$ El rey Egbert estableció una dinastía fuerte en torno al trono de Wessex, que permitió que sus descendientes no solo gobernaran, sino que pudieran hacer frente a las invasiones vikingas, siendo su nieto Alfredo el monarca más ilustre de este linaje. ${ }^{8}$

Tras la muerte de su hermano el rey Æthelred, en el 871, Alfredo llegó al trono de un Wessex a punto de claudicar ante los vikingos. Desde la llegada del Gran ejército, los reinos anglosajones no habían hecho más que perder terreno frente a los nórdicos, en una serie de campañas que tuvieron como resultado la conquista de los reinos de Northumbria, Anglia Oriental y la práctica totalidad de Mercia, así como el saqueo generalizado de casi todo el territorio sajón, quedando únicamente el reino de Wessex con autonomía propia.

Tras una serie de batallas que no decantaron la balanza a favor de ninguno de los bandos, Alfredo se vio en la necesidad de negociar el cese de las hostilidades en varias ocasiones, método que no siempre se reveló efectivo a pesar de la entrega de rehenes o el préstamo de juramentos, e incluso llegó a pagar el conocido danegeld ${ }^{9}$ para evitar los saqueos. ${ }^{10}$

En enero del 878 el caudillo nórdico de Anglia Oriental, Guthrum, que ya había intentado infructuosamente asaltar Wessex, lanza un ataque sobre el baluarte real de Chippenham, movimiento que tomó a Alfredo por sorpresa y lo obligó a huir y buscar refugio en los pantanos de Somerset. Desde allí consiguió reunir un ejército y ese mismo año derrotó a las huestes de Guthrum en la batalla de Edington, que consolidó la posición de Alfredo como rey de los anglosajones, aseguró la independencia del reino de Wessex mediante la firma de un tratado que delimitaba las fronteras de dicho reino y del territorio conocido como Danelaw, ${ }^{11}$ y supuso el bautismo del caudillo vikingo. ${ }^{12}$

Tras la batalla de Edington, Alfredo llevó a cabo una serie de reformas con la intención de fortalecer su posición frente a los nórdicos. Estas reformas consistieron por un lado en la creación de una red de fortalezas, llamadas burhs, que permitían un mayor control del territorio y que entorpecían las razias vikingas. Con el tiempo estas fortalezas se convertirán en importantes centros de comercio e incluso llegaron a prosperar y

\footnotetext{
Título anglosajón que designaba la supremacía temporal de un rey anglosajón sobre el resto. Ibidem, p. 58 .

8 Ibidem, pp. 96-97.

9 Este término aparece registrado en los anales ingleses y significa literalmente "oro danés". Consistía en el pago de una cantidad de dinero (normalmente plata) a los vikingos para que abandonaran un territorio, y así los pobladores evitaban el saqueo de sus tierras. Esta fue una práctica muy extendida tanto en Inglaterra como en el imperio franco. Menezes de Oliveira, "Danegeld”, p. 169.

10 Huardar y Vike, Vikingos en Guerra, p. 250.

11 Se designa con este término a todos los territorios ingleses que quedaron bajo el control de los daneses, es decir, bajo la "ley danesa". Se extendería al norte del rio Támesis hasta Chester, aunque las fronteras irán variando a lo largo de los siglos IX y X. Menezes de Oliveira, “Danelaw”, p. 170.

12 Huardar y Vike, Vikingos en Guerra, p. 257.
} 
transformarse en ciudades. ${ }^{13}$ Otra de las medidas será la reorganización del ejército y la construcción de una flota naval para oponerse a los escandinavos en su medio principal, y aunque esta última medida no resultará especialmente efectiva, supondrá el germen de la posterior armada británica. ${ }^{14}$

Durante la década del 890 los vikingos apenas consiguieron grandes éxitos en su lucha contra Wessex, poniendo de manifiesto la eficacia de las medidas de Alfredo, así como el mayor interés de los nórdicos por asentarse en los nuevos territorios adquiridos, en detrimento de continuar con las campañas militares.

Alfredo no solo fue un rey guerrero, sino que demostró un probado interés por la cultura y la preservación del conocimiento. Realizó una profunda reforma educativa entre sus cortesanos, principalmente religiosos, que lo llevó a traducir al inglés antiguo algunas obras latinas como la "Historia Eclesiástica" de Beda el Venerable, elaboró una extensa complicación de crónicas y genealogías, e inició algunas nuevas como la ya mentada Crónica Anglosajona, y también estableció un nuevo código jurídico para los territorios anglosajones. Todo ello formó parte de un programa propagandístico con el objetivo de glorificar el papel de la dinastía de Wessex como salvadores de la Inglaterra cristiana frente a los vikingos paganos. ${ }^{15}$

Según nos cuenta su biógrafo, el Obispo Asser, Alfredo nunca gozó de una muy buena salud y moriría el 26 de octubre del año $899 .{ }^{16}$ A su muerte, su primacía era indiscutible en los reinos anglosajones que comenzaban a aglutinarse en torno al paraguas de Wessex, lo que junto a la probada eficacia de las reformas emprendidas, posibilitó la acometida del proyecto político de la unificación de Inglaterra por parte de sus descendientes.

\section{Trayectoria audiovisual}

Resulta bastante llamativo que un personaje con un peso tan importante en la historia británica y que posee una vida tan narrativamente interesante, que es prácticamente de guion de película, no haya recibido una atención mucho más significativa desde el séptimo arte, máxime cuando Hollywood ha explotado la figura de una buena parte del folklore inglés, como por ejemplo Robin Hood o el sempiterno rey Arturo.

Para entender algunas de las causas de este fenómeno debemos retrotraernos al siglo XIX, a una Inglaterra en plena época victoriana, donde la figura del rey Alfredo será escogida como ejemplo de los valores sociales, políticos y religiosos de la sociedad del momento. En esta etapa se produce un redescubrimiento de la Edad Media en una búsqueda de las raíces nacionales y de una significación cultural y étnica común de los ingleses, mediante la puesta en valor de figuras icónicas del pasado cuyo relato vital encaje en los mecanismos ideológicos y patrióticos de las élites intelectuales. Siendo

\footnotetext{
Domínguez GonZÁlez, La Inglaterra anglosajona, pp. 113-114.

Cunliffe, Océano, pp. 457-458.

15 Haywood, Los Hombres del Norte, p. 99.

16 Ibidem, p. 102.
} 
la historia de Alfredo un relato de oposición y resiliencia frente a los peligros de una amenaza externa, de la planificación y construcción de un proyecto de unidad político y del ejemplo de una vida consagrada a la religión, no es de extrañar que se creara una sinergia entre ambos mundos que desembocó en un auténtico culto a la personalidad del monarca. ${ }^{17}$ Un ejemplo ilustrativo es la definición del historiador decimonónico Edward Augustus Freeman, que catalogo al rey sajón como "The most perfect carácter in history" ${ }^{\prime \prime} \mathrm{o}$ las palabras del Obispo de Londres, Mandell Creighton, a cerca de Alfredo:

"Alfred was a man who displayed all the characteristics which were most true of Englishmen. He drove back the invader by his persistency; he watched over the development of his people in every way; he was great as an administrator, great as a practical diplomatist, great as a legislator, and, best of all, great as a modest Christian man, as one who was most interested in developing the highest and best energies of his people, who was, in every way, in fact, a father of his country". ${ }^{9}$

El hito más significativo de esta corriente devocional se produjo con la conmemoración de los mil años de la muerte del monarca, en los que la ciudad de Winchester organizó una serie de festejos durante tres días. Miles de personas participaron de los eventos organizados entre los que podían encontrarse políticos, militares, invitados internacionales provenientes de Norte América o Australia, académicos y demás notables del país; todo ello bajo la aprobación explícita de la propia reina Victoria. Las festividades culminaron el 20 de septiembre de 1901, con un discurso del ex primer ministro Lord Rosebury y la inauguración de una estatua del rey Alfredo, que hoy día continúa expuesta en la ciudad. Esta celebración supuso, por un lado, el clímax de los diferentes intereses y modas generados en torno al culto a Alfredo, y por otro, el cenit de este mismo culto, ya que a partir del siglo XX la popularidad y fama del monarca irán decayendo. ${ }^{20}$

Una de las causas que podrían explicar este descenso del interés se encontraría en la producción literaria sobre su figura, que si bien relativamente prolífica en esta época, no fue una literatura de gran calidad, sino que se trataba más bien de obras de entretenimiento con la intención de sacar provecho de las obras patrióticas. ${ }^{21}$ Por otro lado, fue tal la sinergia creada entre Alfredo y los valores culturales de la Inglaterra victoriana que no se permitía su uso como voz crítica contra el sistema, y cualquier intento de tergiversación o manipulación de la figura histórica era rechazado. Junto al hecho de ser un personaje

\footnotetext{
17 Este tipo de uso de la figura de Alfredo no es un fenómeno genuino de la época victoriana, sino que podemos rastrear una larga tradición del empleo de este personaje como sustento y justificación de diversas agendas políticas. Para saber más consulte KING, King Alfred in Early-Modern and Enlighhtenment Britain.

18 Freeman, The History of the Norman Conquest..., p. 51.

19 Yorke, "The "Old North" from the Saxon South", p. 141.

20 PARKer, The Day of a Thousand Years...

21 Yorke, "The "Old North" from the Saxon South", p. 134.
} 
bien conocido debido a la gran cantidad de crónicas y manuscritos históricos que nos hablan de él, el rey Alfredo cayó en manos de un academicismo feroz que destruyó toda posibilidad de mitologizar o fantasear con la vida de este personaje, creando una faceta más "literaria" y seguramente más atrayente para el público en general. ${ }^{22}$ En mi opinión, esto tendrá una clara repercusión en cuanto a su trayectoria cinematográfica ya que el cine va a buscar constantemente inspiración en las artes precedentes (y con el paso del tiempo en las contemporáneas también), siendo el género literario (especialmente la literatura del romanticismo y la de temática caballeresca) una de las principales en ser adaptadas a la gran pantalla, por lo que no es de extrañar el éxito y la continuidad de figuras como el rey Arturo ${ }^{23}$ en el séptimo arte.

Junto a esto, también podríamos destacar algunas causas coyunturales que no redundaron en beneficio de la admiración hacia el monarca. Por un lado, hacia finales del siglo XIX se produce una reevaluación del periodo normando y de su papel tanto en la historia como en la cultura inglesa, superándose en gran medida la teoría del "Yugo Normando" (Norman Yoke), ${ }^{24}$ en detrimento de la cultura anglosajona. Este cambio de actitud se vio acrecentado por el establecimiento de la triple entete y la entente cordiale a comienzos del siglo XX, lo que redefinió las relaciones anglo-francesas. ${ }^{25}$

Por el otro lado, el enfrentamiento en dos guerras mundiales contra Alemania marcó de manera decisiva la forma de ver el pasado sajón del país. Se desarrolló una cautela importante a la hora de glorificar, conmemorar o ubicar la identidad nacional con cualquier evento, etapa o personaje que pudiera ser considerado como germánico. ${ }^{26}$ Esto se debe al enaltecimiento de los valores teutónicos y a la búsqueda de una identidad británica basada, en gran medida, en el atractivo de una herencia racial germana, que aconteció durante el periodo victoriano, de claro talante germanófilo. No es de extrañar que la utilización de estos mismos valores y teorías por parte del movimiento Völkisch y su adopción por el estado nazi alemán, supusieran su tajante rechazo por parte de una Inglaterra vencedora contra el fascismo. Por tanto, el rey Alfredo, a todas luces sajón y por tanto germano, quedó sentenciado a un ostracismo involuntario que estigmatizó a este personaje durante las siguientes décadas.

Durante la década de los 50 la industria cinematográfica hollywoodiense se encuentra en una etapa dorada (ya que, tras la guerra, las industrias europeas no estaban en condiciones), que trae de vuelta el cine épico en su mejor versión. Relatos sobre aventuras, espadachines y romances con telones de fondo históricos, que sacaron el máximo partido

\footnotetext{
22 Parker, "England's Darling": The Victorian cult of Alfred the Great, p. 202.

23 Entre los años 1902 y 2000 se publicaron en torno a cuarenta obras sobre el rey Alfredo mientras que las obras artúricas se contaban por miles. Ibidem, p. 205.

24 Esta teoría hace referencia a la idea de que las libertades tradicionales inglesas se perdieron con la llegada de los normandos, creando una imagen totalmente romantizada de la Inglaterra anglosajona. Esta teoría fue popularizada por novelas como Ivanhoe, de Sir Walter Scott, o Hereward the Wake: the Last of the English, de Charles Kingsley. Para saber más consulte Simmons, Reversing the Conquest: Saxons and Normans in Nineteenth-Century British literatura.

25 PARKER, "England's Darling": The Victorian cult of Alfred the Great, p. 203.

26 Ibidem, pp. 207-208.
} 
al uso de nuevas tecnologías, dieron como resultado películas coloristas y preciosistas que apostaron por la espectacularidad de nuevos formatos visuales (cinemascope), en su disputa con la televisión. ${ }^{27}$

Este cine centró su atención, mayoritariamente, en el periodo medieval atraído por esa imagen decimonónica de tiempos remotos, sombríos e incluso fantásticos, que en ocasiones parece estar alojado en un espacio fuera de la propia historia, lo que produce un sustrato de calidad para la creación de sinergias con el presente contemporáneo. ${ }^{28}$ No es de extrañar que las principales producciones de esta época estuvieran ambientadas en el medievo inglés ya que, a través de unos mecanismos culturales y políticos comunes, heredados de su pasado colonial británico, EEUU pudo crear un reflejo ideológico y nacionalista de sí misma, a través del cine, sirviéndose de este escenario histórico. ${ }^{29}$

Este contexto cinematográfico y cultural resultaba perfecto para recuperar la figura del rey Alfredo y devolverle parte de la popularidad perdida, máxime cuando sus enemigos acérrimos, los vikingos, habían vuelto por todo lo alto con el estreno de la película de Richard Fleischer The Vikings (1958). ${ }^{30}$ Pero una vez más este personaje resultó completamente ignorado, en una señal inequívoca de que su imagen no gozaba de buena salud y que seguía perdiendo terreno frente al protagonista indiscutible de esta etapa, el rey Arturo. ${ }^{31}$

El monarca britano siempre contó a su favor con su carácter puramente mitológico, lo que artísticamente resulto muy llamativo ante la innecesaria rigurosidad histórica empleada para representar a este personaje, que lo convirtió en una figura maleable y apta para todo tipo de contextos, frente a la austeridad y el encorsetamiento de la figura del rey Alfredo, mucho más dependiente de las crónicas medievales. ${ }^{32}$ Esto podemos verlo claramente en cómo el cine, desde prácticamente sus inicios, ha puesto el foco de atención en los caballeros de la mesa redonda, pero más como punto de partida desde el que contar historias, que con un afán de ser fiel a la historia de Arturo. ${ }^{33}$

\footnotetext{
7 Barrio BARrio, "The Middle Ages in USA Cinema", pp. 237-238.

2 Alonso, Mastache y Alonso, La Edad Media en el Cine, pp. 11-12.

9 Aronstein, Hollywood knights..., pp. 1-2

30 Esta película supuso un éxito de taquilla, que aunque no consiguió el mismo respaldo por la crítica, se convirtió en una producción muy popular entre el público joven y fue la precursora de un gran número de producciones sobre temática vikinga. COMA, Los vikingos-Scarface, p. 61.

31 Durante el periodo en torno a la segunda guerra mundial, los vikingos y Alfredo llevaron unas trayectorias muy similares en lo referente a su afinidad y uso por parte de regímenes fascistas y su posterior "olvido" en los medios culturales y cinematográficos. A pesar de las décadas de silencio, los vikingos volvieron a ser rescatados por la gran pantalla y su imagen fue en buena medida revalorizada de nuevo. En cambio, Alfredo, tal como hemos comentado, seguiría sumido en el oscurantismo. Tal vez, la mayor dependencia de los vikingos con la arqueología les haya otorgado un mayor interés ante la posibilidad de la novedad y la fascinación del hallazgo (no olvidemos que durante la década de los 60 se produjeron importantes descubrimientos arqueológicos en torno a la cultura nórdica), frente a una Alfredo que poco nuevo tiene que aportar a su historia.

32 PARKer, "England's Darling": The Victorian cult of Alfred the Great, p. 202.

33 Míguez, "Tras las brumas de Avalon...,", p. 2
} 
Tendremos que esperar a finales de la década de los 60 para encontrar la primera aparición cinematográfica de Alfredo. Tras el colapso del género épico, a raíz de los problemas de rodaje y del elevado coste de la película Cleopatra (Joseph L. Mankiewicz, 1963), ${ }^{34}$ la industria Hollywoodiense, más concretamente su extensión británica, ${ }^{35}$ se adentraron en un nuevo ciclo fílmico dedicado a la realeza inglesa, dando lugar a producciones caracterizadas por su tono intimista, su cuidado diseño de producción, un mayor énfasis en el diálogo erudito sobre la acción y la presencia de actores capaces como Richard Burton, Peter O'Toole y Paul Scofield. ${ }^{36}$ Sera en este contexto donde surgirá Alfred the Great (1969), el primer y único largometraje de la historia dedicado íntegramente a la figura de Alfredo el Grande.

Este biopic, a cargo del director británico Clive Donner, nos invita a conocer la vida del rey Alfredo (interpretado por David Hemmings) desde su llegada al trono hasta su gran victoria en Edington, en un reinado marcado por la confrontación con los invasores vikingos y su pugna personal contra el líder danés Guthrum (Michael York), en un film de ritmo pausado pero cargado de fuerza en sus escenas de batalla.

El guion estuvo a cargo de Ken Taylor y James R. Webb que se basaron en la obra de historia popular Alfred the Great: The King and His England (1956), de Eleanor Shipley Duckett. ${ }^{37}$ Desde luego no fue la única obra de referencia ya que podemos ver claras alusiones ${ }^{38}$ a otro texto bien conocido, The Ballad of the White Horse (G.K. Chesterton, 1911), una obra culmen de la literatura alfrediana, epítome del culto a su figura en la etapa victoriana.$^{39}$ Las referencias decimonónicas son abundantes en esta película, y es que muchos de los tópicos dramáticos que fueron creados en un intento de hacer más atractiva la historia del monarca para el público en general, serán emulados en igual medida en este film. La profesora Barbara Yorke lo detalla de la siguiente manera:

"Most productions found it necessary to add to dramatic interest by inclusion of one or more pairs of young lovers separated by the exigencies of war, and the capture of Alfred's wife with a threat to her virtue from a lascivious Viking leader was also a common addition to the plot. The dramatic potential of the plays was further enhanced by references to Viking paganism with the

\footnotetext{
34 BARRIo BARRIo, "Introducción al cine histórico: El Colosal", p. 44.

35 En la década de los 50 y 60 Hollywood llevará a cabo una política de internacionalización y externacionalización de sus producciones, e Inglaterra sería el lugar predilecto para ello. Como resultado se crearon estudios en Reino Unido financiados con capital americano, como por ejemplo los estudios Borehamwood, filial británica de MGM. StuBBs, Hollywood and the Invention of England..., pp. 94-96

36 Ibidem, pp. 128-129.

37 SNYder, "To be, or not to be -King...", p. 39.

38 Nos referimos principalmente a la escena que recrea la batalla de Ashdown, que en el film tiene lugar en el conocido como Caballo Blanco de Uffington (una enorme figura con forma de caballo, gravada en lo alto de una colina y rellenada de tiza blanca), posiblemente inspirado en la tradición local recogida en la obra de G.K. Chesterton.

39 Parker, "England's Darling": The Victorian cult of Alfred the Great, p. 207.
} 
"Raven Banner", pagan ceremonies and the threat of human sacrifice being very much to the fore". ${ }^{40}$

La dureza de la realidad política y social de la época, con las imágenes en televisión de la guerra de Vietnam, las protestas estudiantiles o el asesinato de Luther King, marcó la película y condicionara el carácter hosco y frío de un rey Alfredo que se debate constantemente en la dicotomía entre ser rey o dedicarse a la vida eclesiástica, aceptar sus deberes frente a sus pasiones, que en ocasiones lo llevan a ser orgulloso y cruel, en una especie de reflejo distorsionado del Hamlet de Shakespeare. ${ }^{41}$ No solo la figura de Alfredo estará imbuida de la brutalidad de su época, sino que sus principales antagonistas se verán sometidos a un proceso estético de militarización que convertirá las huestes vikingas en todo un ejército invasor, cruel y sanguinario, en lo que algunos académicos han visto como un intento de "nazificar" a los vikingos en esta cinta. ${ }^{42}$

El balance final no fue bueno para esta producción, que no tuvo una muy buena acogida por parte de la crítica (aunque algunos medios alabaran el carácter antiheroico del protagonista), ni tampoco cosechó el éxito en taquilla. ${ }^{43}$ En definitiva, una película destinada al olvido y que no consiguió revitalizar la figura de un casi olvidado rey Alfredo.

Visto que la experiencia cinematográfica había resultado un tanto efímera e intranscendente, las dudas sobre la viabilidad del personaje en el medio audiovisual eran más que patentes y su supervivencia no estaba asegurada. Pero el nuevo fenómeno de las series de televisión, en una actuación que podría calificarse casi como necromántica, resucitarían de nuevo al rey Alfredo para adaptar su figura y su época a la pequeña pantalla. Así, tras más de cuarenta años, este rey volvería a los sets de rodaje.

Desde más o menos finales de los años 90 y hasta nuestro más inmediato presente, se ha producido toda una revolución en torno a las series de televisión. Una etapa que parece continuar vigente y que podríamos denominar, a falta de un consenso académico, como una tercera edad dorada de la ficción televisiva. ${ }^{44}$ Esta nueva fase se caracteriza por la generalización e implementación del uso de nuevas tecnologías, principalmente internet, que han modificado las formas de consumo tradicionales de estas ficciones televisivas, no solo mejorando la disponibilidad de las producciones y su popularización a través de las redes sociales, sino deslocalizando completamente el propio aparato de televisión ante una multiplicidad inmensa de dispositivos de reproducción portátiles o fijos. El uso de nuevas tecnologías también ha permitido una mayor ambición estética en las producciones, generalizando el uso de efectos especiales, y un horizonte narrativo mucho más amplio y profundo de lo que el formato televisivo tradicional venia ofreciendo. ${ }^{45}$

\footnotetext{
Yorke, "The "Old North" from the Saxon South", p. 133.

SNYDER, "To be, or not to be -King...", p. 42.

Alberth, Knight at the Movies, p. 52.

SNYDER, "To be, or not to be -King...", p. 44.

García Martínez, "El fenómeno de la serialidad...", p. 1.

Ibidem, pp. 2-4.
} 
Todo esto ha discurrido de forma paralela junto a la tendencia comercial inherente al medio, que se ha desarrollado en el marco de un libre mercado de competencia entre cadenas, que han recurrido a la búsqueda de la innovación y la emulación como forma de crear una identidad propia que las distinga de las demás. Un claro ejemplo de esto será el canal History Channel y su decisión de complementar sus habituales documentales de historia con series temáticas como Vikings. ${ }^{46}$

El creador de esta serie será el también británico Michael Hirst, conocido por producciones anteriores como The Tudors (2007-2010), donde exploraremos la cultura vikinga a través de uno de sus personajes más icónicos, el famoso Ragnarr Loðbrók, en una coproducción entre Irlanda y Canadá, cuya primera temporada se estrenó en 2013 y se espera la emisión de la última a finales del presente año $2020 .{ }^{47}$

Dada la estrecha relación histórica entre los vikingos e Inglaterra y dado que el rey Alfredo es el representante por antonomasia de los anglosajones de este periodo, no es de extrañar que esta serie recupere la figura del monarca, pero en ningún caso con el rol de protagonista absoluto, sino como el de un personaje de relevancia, pero colateral, de la historia nórdica. No debemos caer en el simplismo de otorgarle el papel de antagonista, pues esos planteamientos tan maniqueos son más propios del cine que de las series, ya que el formato de larga duración empleado por las ficciones televisivas permite una mayor matización y complejidad de sus personajes, desdibujando en gran medida ese paradigma antagónico entre buenos-malos, paganos-cristianos, barbarie-civilización, etc.

La construcción del personaje de Alfredo en Vikings va a ser un tanto confusa pues pivotará entre dos personajes: El rey Egbert (Linus Roache) y el propio rey Alfredo (Ferdia Walsh-Peelo), ya que el primero presentará una serie de atribuciones propias de su nieto, que serán discutidas más adelante, en lo referente a la monarquía de Wessex y la unificación de Inglaterra. En mi opinión, esto se debe a las dos fases en las que podemos dividir la propia serie: la primera, centrada en la vida y andanzas de su protagonista Ragnar, y una segunda, en la que los hijos asumirán el protagonismo y serán el hilo conductor del resto de tramas. Gran parte del argumento de esa primera etapa se centra en las actividades de Ragnar en Inglaterra; es aquí donde se hace palpable la necesidad de un personaje que represente los arquetipos anglosajones y que interactúe, y de alguna manera se oponga, a los vikingos. Dado que las figuras de Alfredo y Ragnar no son coetáneas, se aboga por la utilización del rey Egbert como justificación históricocronológica, ${ }^{48} \mathrm{y}$ aunque se dote a este personaje de personalidad propia se creara a partir de unos parámetros referenciales de la figura de Alfredo, ${ }^{49}$ lo cual no es de extrañar si tenemos en cuenta la información que conocemos de un monarca y del otro.

\footnotetext{
$46 \quad$ Ibidem, p. 4.

47 https://www.fotogramas.es/series-tv-noticias/a31019795/vikingos-6-estreno-segunda-parte/

48 A la llegada de los vikingos a Inglaterra en los primeros compases del siglo IX, será Egbert quien gobierne en Wessex. Dado que la serie "propone" una primera llegada de los nórdicos a suelo británico capitaneada por Ragnar, no es casualidad la elección de la figura del rey Egbert.

49 Asin, Intertextuality of the sagas of Raganar Lodbrok by Ben Waggoner..., pp. 75-76.
} 
En la segunda etapa de la serie ya sí que encontramos al personaje del propio Alfredo, en una reconstrucción más apegada a la imagen ofrecida por las crónicas y por su biógrafo Asser, a pesar de las licencias y reescrituras presentes, típicas de la necesaria adaptación a un formato audiovisual y comercial. Si bien es cierto que la serie recoge logros y eventos del personaje histórico, da la sensación de que toda la "grandeza" de este personaje queda diluida en una serie de tramas palaciegas sin sentido, en un intento vano por asemejarse a otras fórmulas de éxito como la de Game of Thrones. Aún deben trazarse las últimas líneas de actuación de este personaje en la que será la segunda parte de la sexta y última temporada, aunque todo parece indicar que no estamos ante un rey Alfredo que quedará para la posteridad.

Está fuera de toda duda que el éxito de la serie Vikings ha sido total, no solo a nivel de recaudación y espectadores, sino en el profundo impacto social que ha creado, elevando a la cultura vikinga a una nueva edad dorada como no habían conocido desde el siglo XIX. El éxito de su popularidad es perfectamente perceptible, aun hoy día, en la cantidad de producciones colaterales que han surgido y no solo a nivel audiovisual sino videojuegos, comics, libros, merchandising, etc. Si juntamos esto, con ese paradigma entre innovación y emulación que caracteriza a las series de hoy día, obtendremos una imagen clara del contexto en el que surge la otra producción que se trata en este artículo, The Last Kingdom..$^{50}$

Esta serie de televisión es resultado de una coproducción entre Carnival Films y BBC América para el canal de televisión británico BBC Two, ${ }^{51}$ cuya primera temporada se estrenó en el año 2015. Para su segunda temporada la plataforma de streaming online, Netflix, se unió como coproductor a la serie ${ }^{52}$ y en adelante se convertirá en el principal distribuidor de esta en buena parte de Europa ${ }^{53}$ y América. Con un total de cuatro temporadas estrenadas por el momento, Netflix ha confirmado la renovación para una quinta, que se espera en torno a finales del próximo año $2021 .^{54}$

TLK adapta a la pequeña pantalla la saga de novelas históricas del escritor inglés Bernard Cornwell, "Sajones, Vikingos y Normandos". ${ }^{55}$ Esta se ambienta en una Inglaterra en plena invasión vikinga donde a través de su protagonista, Uthred de Bebbanburg (Alexander Dreymon), un joven noble sajón que será capturado y criado por los daneses pero que pronto se verá obligado a escoger entre su familia y su país de origen, nos

\footnotetext{
50 De ahora en adelante usaremos la contracción TLK para referirnos a esta serie, buscando la comodidad y agilización de la lectura de este texto.

51 https://deadline.com/2015/08/the-last-kingdom-trailer-downton-abbey-producers-bbc-america-alexander-dreymon-1201500202/

52 https://deadline.com/2016/06/netflix-co-produce-the-last-kingdom-bbc-two-alexander-dreymoncarnival-films-bbc-america-1201769660/

53 En el caso de España la distribución y estreno de la serie se produjo a través de Netflix, pero en 2017 la televisión autonómica catalana TV3 incluyo en su parrilla esta ficción histórica. https://www.ccma.cat/ tv3/estiu-2017/the-last-kingdom/seccio-especial/3770/4890/

$54 \mathrm{https}: / \mathrm{www} \cdot$ radiotimes.com/news/on-demand/2020-05-26/the-last-kingdom-season-five/

55 Esta serie literaria cuenta en la actualidad con doce novelas y se espera una nueva a finales de 2020. Por el momento solo han sido traducidas al español las diez primeras.
} 
adentraremos en los entresijos de un conflicto que duró varios siglos y que marcó la historia de Inglaterra.

Dada la especificidad cronológica y geográfica del contexto en el que TLK se desarrolla, era obvia la aparición del personaje de Alfredo (David Dawson). Al igual que ocurre en la serie anterior, Alfredo no será el protagonista de esta ficción histórica, aunque eso sí, esta será la versión cinematográfica sobre este rey más completa, profunda y detallada de cuantas hemos visto. Esto se debe al estrecho paralelismo existente entre las novelas y la serie de televisión, lo que ha posibilitado la creación de un personaje de ficción dramático bien construido y que ha dispuesto del tiempo necesario, gracias al formato serie, para un desarrollo acorde con el personaje.

El Alfredo de Cornwell, y por tanto el de TLK, se presenta como un personaje muy alejado de los valores heroicos de la época victoriana, que responde más a una figura producto de las nuevas visiones historicistas y con un enfoque mucho más moderno y acorde al siglo XXI. El hecho de acercarnos a Alfredo a través de la visión de Uthred ha permitido una enorme deconstrucción del personaje, que incluso ha dejado espacio para la crítica y el reproche, pero manteniendo, a mi juicio, la dignidad y grandilocuencia de este personaje histórico, que no en vano es apodado "el grande".

\section{El Alfredo cinematográfico}

Hemos comprobado que las representaciones audiovisuales del rey Alfredo son variadas y diferentes entre sí, pero a pesar de ello existen ciertos elementos comunes en la historia de este rey que han supuesto un leitmotiv constante en las ficciones cinematográficas en torno a este personaje.

Sin duda alguna, el asociar la unificación de Inglaterra con el rey Alfredo es la característica más destacada de este personaje. En términos históricos el rey Alfredo nunca llevó a cabo dicha unificación. Los laureles de este logro recayeron por un lado en el hijo de Alfredo, Eduardo, que logró junto a su hermana Æthelflæd, señora de Mercia, recuperar los territorios sajones al sur del Humber, ahora bajo la primacía de la casa real de Wessex, y dejar solo Northumbria como el ultimo reino en control directo de los caudillos nórdicos. ${ }^{56}$ Y por el otro lado, recayeron en Athelstan, el hijo de Eduardo, quien de facto logrará unificar Inglaterra tras su victoria en la batalla de Brunanburh (937), aunque a su muerte esta unión no durará frente a la llegada de nuevas invasiones vikingas. ${ }^{57}$

Si bien Alfredo no es el ejecutor de la unificación de Inglaterra, sí que será el responsable de la creación de un proyecto político e ideológico que persiguió la creación de una identidad nacional común para los ingleses. Para ello se apoya en una reforma educativa integral de su corte, en la compilación de anales, crónicas y genealogías con fines totalmente propagandísticos y legitimadores, que justificaban la pertenecía a un

\footnotetext{
56 Domínguez GonzÁlez, La Inglaterra anglosajona, pp. 118-121.

57 Ibidem, p. 127.
} 
grupo étnico común,$^{58}$ obviamente no de base biológica pero si basado en un idioma, unas costumbres y una religión compartida. ${ }^{59}$

No cabe duda que los condicionantes políticos y los eventos históricos que marcaron el reinado de Alfredo, crearon un caldo de cultivo perfecto que posibilito la proliferación y el triunfo de esa idea sobre la unificación. Igualmente claro es que la explotación de la figura de Alfredo como emblema político en los siglos posteriores, facilitó el arraigo de la equívoca idea de este rey como artífice factual de este hecho histórico, del que sus versiones cinematográficas hacen gala.

El caso más flagrante de todos sin lugar a dudas, corresponde al film del 1969 donde unos intertítulos, al comienzo y al final de la película, nos dicen lo siguiente:

"In the 9th century England as a nation did not yet exist. The land was then divided into several independent kingdoms, of which the greatest and richest was Wessex."

"Here lived a prince named Alfred, to whom came a vision of a united country living under one law..."

"But he was only 22 years old in the year 871, when savage, pagan Danes crossed the North Sea to pillage his land."

Al final de la película:

Here (en la batalla de Edington) England was united and Alfred was its only sovereign to be called 'the Great'”.

A parte de la obvia función de contextualizar históricamente la película, estos intertítulos nos indican de una forma nada sutil que la historia de Alfredo es la historia de la unificación de Inglaterra, una unificación que no se basa en la idea de pertenencia a un grupo étnico concreto, sino en el establecimiento de un código jurídico común, que solo puede llevar a cabo la dinastía de Wessex, y que se producirá tras la ardua lucha contra el invasor pagano. Este planteamiento ideológico es un claro reflejo de los valores

58 El termino empleado para la designación de este grupo étnico anglosajón fue el de Angelcynn, adoptado por Beda en su Historia ecclesiastica gentis Anglorum. Las características principales sobre las que esta concepción etnográfica se basa son: su oposición a un "otro" (vikingos en este caso) que por contraste define un "nosotros" (anglosajones), el reconocimiento y deber para con el rey (Alfredo), el establecimiento de unas fronteras físicas que separen el "nosotros" del "ellos" (Danelaw), la legitimidad de la dinastía reinante y sus monarcas (para ello se toma la figura de Egbert como el rey legitimador de la dinastía) y por supuesto, la selección de este grupo como "pueblo elegido de Dios" y su oposición a los paganos. Todo esto se fragua a través de un muy estudiado corpus documental que fue distribuido y completado por las elites intelectuales, básicamente las eclesiásticas, durante todo el periodo alfrediano. TimofeEvA, "Alfredian Press on the Vikings", pp. 237-238.

59 Konshum, "Constructing Early Anglo-Saxon Identity...”, p. 157. 
victorianos y sus atribuciones histórico-políticas a la figura del rey Alfredo, cuestión que esta película reproduce fielmente dando lugar a un ejercicio narrativo y estético más propio de una novela del siglo XIX, solo que adaptada al formato cinematográfico. Podríamos pensar que el paso del tiempo ayudó a la superación de esta idea de Alfredo como unificador, teniendo en cuenta todo el revisionismo académico al que ha sido sometido este personaje y su deconstrucción como el otrora héroe del imperio británico, pero no ha sido así. Es cierto que las series han añadido algunos matices a este hecho histórico, o lo han explorado más en profundidad, como ha sido el caso de Vikings donde se nos presenta al rey Egbert como el ideólogo tras esa visión de Inglaterra.

Debemos ser cautos ante la idea del Egbert histórico como rey de una Inglaterra unificada. A pesar de su meteórica trayectoria y de los logros conseguidos, este monarca nunca se intituló más allá de Bretwalda, un título que reconocía la primacía de este monarca sobre el resto pero más como un primus inter pares que como un rey de todos los anglosajones, y que en ningún caso lo presentaba ni legitimaba como señor de toda Inglaterra. ${ }^{60} \mathrm{~A}$ pesar de ello, la ficción de History Channel nos presenta la imagen de un rey ambicioso que consigue imponerse a sus rivales políticos, pero que también es muy consciente del valor de preservar y difundir el conocimiento y del papel que la institución eclesiástica juega en esto. Todas estas atribuciones propias del rey Alfredo, convierten al personaje de Egbert en una especie de "proto" Alfredo, que ante la imposibilidad de llevar a cabo sus ambiciones políticas, debido a los devenires argumentales de la serie, lega esta tarea en su nieto, de forma que la unificación política de Inglaterra no será consecuencia de la proyección ideológica o factual de los logros de Alfredo, sino del legado político que recibe de su abuelo y que el solo se limitará a llevar a término. En TLK este leitmotiv continuará presente, pero desde una perspectiva algo más concordante con los hechos históricos dado el apego a los libros y su talante más historicista en lo referente a la representación del rey Alfredo. Desde el principio de la serie, concretamente en el segundo capítulo, ya se nos deja claro cuál es el "sueño" que ambiciona Alfredo con respecto al futuro de Inglaterra, pero más allá de eso, esta idea se convertirá en un elemento subyacente de la figura de Alfredo, pero en ningún caso el motor ideológico que justifica y motiva las acciones de este. La idea de la unificación volverá a retomar mayor trascendencia a la muerte de Alfredo, y de nuevo, se presentará en forma del legado que recibirá su hijo Eduardo, que sí actuará movido por la intención de mantener y cumplir con esa herencia.

Resulta curioso el cambio de paradigma que se produce entre la obra de Donner, totalmente suscrita a los parámetros decimonónicos de representación e ideologización, en el que la unificación de Inglaterra es obra de la actuación visionaria del rey Alfredo, frente a la series de televisión donde a través de los binomios Egbert-Alfredo o Alfredo-Eduardo, se proyecta esta unificación como una construcción conjunta y en varios tiempos, en la que una gran figura precedente establece las bases del proyecto pero serán sus descendientes los que deberán culminarlo.

60 Domínguez GonzÁlez, La Inglaterra anglosajona, p. 96. 
Otro gran hito de la vida de Alfredo que ha sido representado hasta la extenuación será su huida a los pantanos del Somerset. Este evento, que se ha tornado en material de leyenda, ha permitido que diferentes relatos y ficciones surjan alrededor de la figura del rey. La más conocida de todas relata cómo a Alfredo, refugiado en casa de una campesina, se le encarga que vigile unas tortas que estaban en el fuego, y este, cansado, se duerme, por lo que las tortas se queman y recibe una buena reprimenda por parte de la campesina. Otra historia ambientada en los humedales narra que San Cutberto se le apareció a Alfredo y le promete ayuda contra los vikingos que habían asaltado su monasterio en Lindisfarne. Un tercer relato cuenta como Alfredo se disfraza de juglar y se cuela en el campamento de Guthrum para averiguar sus planes. ${ }^{61}$

Estas leyendas fueron muy valoradas a nivel popular en el siglo XIX ya que permitían cierto grado de imaginación e incluso comedia en las obras menos serias, ${ }^{62}$ frente a la figura de un Alfredo en manos de los académicos, que reivindicaban una versión realista y desmitificada del monarca. Creo que las palabras del autor victoriano, Gordon Stables, ${ }^{63}$ representan muy bien esto cuando dice: "Who would read your dry as-dust history, think you, if there was no ray of romance illuminating its pages here and there?". ${ }^{64}$

El ámbito audiovisual sí que ha mantenido intacto el capítulo de la huida a los pantanos, siendo de obligada presencia. Sin embargo, no ha ocurrido lo mismo en lo referente a las leyendas populares, que no han sido reproducidas de forma explícita, aunque en algunos casos hay leves guiños o reescrituras adaptadas a las tramas propias, pero sí que ha mantenido ese carácter legendario y fantasioso en las nuevas situaciones propuestas desde el medio cinematográfico.

En Alfred the Great la huida a los pantanos se presenta como una consecuencia del mal carácter de Alfredo, que lo llevó a azotar a un noble en público, suponiendo la pérdida del apoyo de sus partidarios. Sin recursos ni hombres, Alfredo se ve imposibilitado para hacer frente a los ataques daneses, por lo que debe retirarse y buscar refugio en los pantanos. Allí será acogido por unos bandidos con los que traba amistad, y servirá para que Alfredo realice un viaje introspectivo que lo llevará a darse cuenta de sus errores, a asumir su papel como rey y proclamar su visión de un reino donde todos sean iguales, en esa visión moderna del cine donde se sigue apelando a un sentimiento de igualdad en la Edad Media. ${ }^{65}$

En Vikings el exilio a los pantanos supone un punto importante, donde de alguna manera se produce el cambio de rol entre Egbert y Alfredo, ya que el primero decidirá quedarse en Wessex donde muere y el segundo saldrá de los pantanos, no directamente como rey, pero si como el claro candidato a ocupar la primacía. Además de esto, durante la estancia en los humedales, se nos presenta a un Alfredo cuya enfermedad se ha agravado

\footnotetext{
Haywood, Los Hombres del Norte, pp. 91-92.

Yorke, "The "Old North" from the Saxon South", p. 133.

63 William Gordon Stables autor de Twixt Daydawn and Light: A Tale of the Times of Alfred the Great publicado en Londres en 1898.

64 PARKer, "England's Darling": The Victorian cult of Alfred the Great, p. 205.

65 SNYDER, "To be, or not to be -King...", p. 41.
} 
considerablemente, peligrando su vida, pero una visión de su padre biológico, el monje Athelstan, no solo conllevará su recuperación, sino que obtendrá importante información sobre los vikingos. Esto es claramente, un reflejo del relato sobre la aparición de San Cutberto, que se evidencia aún más en el hecho de que el personaje de Athelstan es un monje de Lindisfarne, al que los vikingos capturaron para vender como esclavo.

De entre todas las producciones audiovisuales solamente TLK hará alusión al famoso pasaje sobre las tortas quemadas, aunque de una manera totalmente sutil y desprovista de toda moraleja; simplemente, imagino, que como un guiño a la popularidad de esta leyenda. En este caso, la saga literaria sí que rescatará de una forma más tácita y clara la historia de las tortas, y también la del bardo que se cuela en el campamento danés, pero no habrá un correlato fílmico de esto. En cambio, el foco de atención se centra en el fantasioso relato de cómo una bruja britana (Iseult), amante de Uthred, salva la vida de un Eduardo, prácticamente bebé, al que la enfermedad amenazaba su vida.

No es de extrañar que tanto la huida a los pantanos como su consecución en la batalla de Edington hayan sido los pasajes más famosos y repetidos de cuantas obras artísticas hay sobre la figura del rey Alfredo. Narrativamente suponen un binomio muy bien integrado, donde los pantanos representaran la catábasis del personaje, un viaje hacia las debilidades y miserias de este, pero un punto de inflexión del que saldrá reforzado para hacer frente a la culminación del periplo heroico, que se materializará en la victoria alcanzada en la batalla de Edington.

Esta batalla será la gran victoria del reinado de Alfredo, no solo por sus consecuencias históricas en la pugna por el control de Inglaterra contra los daneses, sino por el fuerte impacto mediático y propagandístico que supuso. El Obispo Asser en su obra "Vida del rey Alfredo", la relata de la siguiente manera:

"Luchando ferozmente con una muralla de escudos compacta contra todo el ejército danés, [Alfredo] resistió con decisión durante mucho tiempo; al final logró la victoria por la voluntad de Dios. Destruyó a los daneses con una gran matanza y persiguió a los que huían hasta su fortaleza, abatiéndolos." ${ }^{66}$

Resulta obvio que este hecho en particular haya sido representado en las diferentes versiones audiovisuales ya que la acción y las batallas forman parte integral de las películas históricas, y por supuesto resultan un reclamo estético muy potente. Puede que esta sea el único hito donde se produce un relativo consenso de criterios, en el que más allá de la representación de la batalla en sí, rodada con más o menos medios y destreza técnica, podemos concluir que la batalla de Edington posee una significación común en cuanto a la unificación de Inglaterra y en cuanto al afianzamiento de los valores heroicos y grandilocuentes en la figura del rey Alfredo.

66 Haywood, Los Hombres del Norte, p. 94. 
Una de las consecuencias más notables de esta batalla, será la derrota del que podemos considerar, desde una percepción bastante maniquea, como el archienemigo de Alfredo, Guthrum. Su derrota no supondrá su muerte, en ese clásico duelo cinematográfico entre ambos personajes, sino que supondrá algo con bastante más significado: será bautizado. Este hecho que posee una carga ideológica importante, ya que lanza un mensaje claro de la victoria tácita del cristianismo sobre el paganismo, no ha tenido el mismo eco en sus representaciones fílmicas, ya que en la obra del 69 ni siquiera figura este hecho, y en las series ${ }^{67}$ se retrata desde una perspectiva más contemporánea, convirtiéndolo en un hecho puntual sin mayor trascendencia ideológica.

\section{Conclusiones}

No cabe duda que la figura de Alfredo el Grande es, ha sido, y será una figura importante y de peso tanto en la historia de Inglaterra, como en la historia medieval de Europa o como en la propia historia de los vikingos. Pero tampoco cabe duda que no será un personaje con un fuerte arraigo en el imaginario popular.

Diversos factores, tanto estructurales como coyunturales, han confluido en su figura impidiendo el éxito de su popularidad a lo largo de los siglos XX y XXI, pero debemos destacar uno por encima de los demás: el fuerte apego de este personaje por su propia historia y el rechazo sistemático ante cualquier intento de mitologización o ficcionalidad de su figura, lo que ha lastrado de forma significativa sus representaciones artísticas, literarias y cinematográficas. Es con personajes como este donde queda patente que la sinergia entre el cine y la historia ha de producirse a través de la ficción y no a través de las polvorientas y secas crónicas medievales.

Desde luego Alfredo no ha sido muy prolijo en cuanto a sus representaciones cinematográficas, y más si lo comparamos con otras figuras como el rey Arturo o los vikingos. De hecho, tras su primera aparición en pantalla, que podríamos considerar algo fallida, nada presagiaba su vuelta a este medio. Puede que los logros de este rey fueran muchos y complejos para un simple film comercial de 120 minutos, pero tras más de cuatro décadas de espera, llegaría el nuevo formato serial de televisión que posibilitó no solo la recuperación de este personaje, sino una representación mucho más extensa y en profundidad de la figura del rey Alfredo.

Paradójicamente, el éxito de Alfredo en el mundo de las ficciones históricas televisivas no se debe a que este personaje haya sido objeto de una revalorización en estas décadas, sino que se debe al nuevo revival nórdico que estamos viviendo en estos años, y al papel colateral que el monarca ocupa en la historia vikinga. Es más que probable que

\footnotetext{
67 Debemos aclarar que en el caso concreto de Vikings, el papel de Guthrum no ha sido representado como tal, sino que los acontecimientos con los que podríamos relacionarlo son llevados a cabo por diferentes personajes según convenga al desarrollo de la trama. En el caso específico del bautismo como señal de sumisión al rey Alfredo, será unos de los hijos de Ragnar, Ubbe, quien protagonice este hecho.
} 
si no fuera por el abrumador éxito de la serie Vikings la figura de Alfredo continuara inmersa en un oscurantismo audiovisual.

Está claro que las series han jugado un papel muy positivo como revulsivo de la figura de Alfredo, pero no es tan claro que estas hayan sido definitorias para afianzar a este personaje en la cultura popular y en el mundo audiovisual. Las dudas sobre si volverá a convertirse en un rey en el olvido son más que patentes y solo el paso del tiempo nos dará una respuesta, aunque espero que no se demore otros cuarenta años.

\section{Bibliografía}

Alberth, John, Knight at the Movies: Medieval History on Film, Nueva York, Routledge, 2003.

Alonso, Juan J., Mastache, Enrique A. y Alonso, Jorge, La Edad Media en el Cine, T\&B Editores, Madrid, 2007.

Aronstein, Susan, Hollywood knights: Arthurian cinema and the politics of nostalgia, Palgrave Macmillan, Nueva York, 2016.

AsIH, Restu Wahyuning, Intertextuality of the sagas of Ragnar Lodbrok by Ben Waggoner and its tv-series version: Vikings (Symbolic interactionism approach), Doctoral Dissertation, State Islamic Institute of Surakarta, 2019.

Barrio Barrio, Juan Antonio, "Introducción al cine histórico: El Colosal”, Anuario de Estudios Medievales, 29 (1999), pp. 35-57.

BARrio BARrio, Juan Antonio, "The Middle Ages in USA Cinema", Imago temporis: medium Aevum, 2 (2008), pp. 229-260.

Coma, Javier, Los vikingos-Scarface, Libros Dirigido, Barcelona, 1996.

Cunliffe, Barry, Océano. Una historia de conectividad entre el Mediterráneo y el Atlántico desde la prehistoria al siglo XVI, Ediciones Desperta Ferro, Madrid, 2019.

Domínguez GonzÁlez, Carlos, La Inglaterra anglosajona. Una síntesis histórica (ss. V-XI), Ediciones de La Ergastula, Madrid, 2015.

Dowham, Clare, "Vikings in England", The Viking World, Stefan Brink (ed.) y Neil Price (ed.), Routledge, Londres, 2012, pp. 341-349.

Freeman, Edward Augustus, The History of the Norman Conquest of England, Its Causes and Its Results, Clarendon Press, Oxford, 1867.

García Martínez, Alberto Nahum, "El fenómeno de la serialidad en la tercera edad de oro de la televisión", La figura del padre nella serialitá televisiva, Enrique Fuster (coord.), Pontificia Universitá della Santa Croce, 2014, pp. 1-20.

HaYwood, John, Los Hombres del Norte. La saga Vikinga (793-1241), Ariel, Barcelona, 2016.

Huardar, Kim y Vike, Vegard, Vikingos en Guerra, Ediciones Desperta Ferro, Madrid, 2019. 
KING, Ian, King Alfred in Early-Modern and Enlightenment Britain: Historiographical Precursors to the Victorian Cult of Alfred, History Senior Thesis, Trinity College, 2018. Konshun, Courtnay, "Constructing Early Anglo-Saxon Identity in the Anglo-Saxon Chronicles", The Land of the English Kin. Studies in Wessex and Anglo-Saxon England in Honour of Professor Barbara Yorke, Alexander Langlands (ed.) y Ryan Lavelle (ed.), Brill, Leiden, 2020, pp. 154-179.

LANGer, Johnni, "Era Viking", Dicionario de Historia e Cultura da Era Viking, Johnni Langer (org.), Hedra, São Paulo, 2018, pp. 212-220.

Menezes de Oliveira, Ricardo Wagner, "Danegeld", Dicionario de Historia e Cultura da Era Viking, Johnni Langer (org.), Hedra, São Paulo, 2018, pp. 169-170.

Menezes de Oliveira, Ricardo Wagner, "Danelaw", Dicionario de Historia e Cultura da Era Viking, Johnni Langer (org.), Hedra, São Paulo, 2018, pp. 170-172.

Míguez, Antonio, "Tras las brumas de Avalon: El mito artúrico a través del cine", Windumanoth, 5 (2019), pp. 2-5.

Parker, JoAnne, "England's darling": The Victorian cult of Alfred the Great, Manchester University Press, 2007.

Parker, JoAnne, "The Day of a Thousand Years: Winchester's 1901 Commemoration of Alfred the Great", Film and Fiction: Reviewing the Middle Ages, Tom Shippey (ed.) y Martin Arnold (associate editor), D.S. Brewer, Cambridge, 2003, pp. 113-136.

Simmons, Clare A., Reversing the Conquest: Saxons and Normans in Nineteenth-Century British Literature, Tesis Doctoral, University of Southern California, 1988.

SNyder, Christopher A., “'To be, or not to be'-King: Clive Donner's Alfred the Great (1969)", The Vikings on Film: Essays on Depictions of the Nordic Middle Ages, Kevin J. Harty (ed.), McFarland, Carolina del Norte, 2014, pp. 39-45.

StuBbs, Jonathan, Hollywood and the Invention of England: Projecting the English Past in American Cinema, 1930-2017, Bloomsbury Academic, Londres, 2019.

Timofeeva, Olga, "Alfredian Press on the Vikings: A Critical Discourse Approach to Outgroup Construction”, Journal of English Linguistics, 44 (2016), pp. 230-253.

Vilar Oliveira, Leandro, "Grande Armada Danesa", Dicionario de Historia e Cultura da Era Viking, Johnni Langer (org.), Hedra, São Paulo, 2018, pp. 323-325.

Yorke, Barbara, "The "Old North" from the Saxon South in Nineteenth-Century Britain", Anglo-Saxons and the North: Essays Reflecting the Theme of the 10th Meeting of the International Society of Anglo-Saxonists in Helsinki, August 2001, Matti Kilpiö (ed.), Leena Kahlas-Tarkka (ed.), Jane Roberts (ed.) y Olga Timofeeva (ed.), Arizona Center for Medieval and Renaissance Studies, 2009, pp. 132-149. 